\title{
Association between Family Environment and Sexual Behaviour of Adolescents in Burkina Faso
}

\author{
Miangotar Yode1, Thomas LeGrand ${ }^{2}$ \\ ${ }^{1}$ Department of Geography, Université de N'Djaména, Ndjamena, Chad \\ ${ }^{2}$ Department of Demography, Université de Montréal, Montréal, Canada \\ Email: yode m@yahoo.fr, tk.legrand@umontreal.ca
}

Received 5 December 2013; revised 26 January 2014; accepted 10 February 2014

Copyright (C) 2014 by authors and Scientific Research Publishing Inc.

This work is licensed under the Creative Commons Attribution International License (CC BY). http://creativecommons.org/licenses/by/4.0/

(c) (i) Open Access

\begin{abstract}
Studies conducted in Africa have demonstrated the existence of a significant association between family environment and the sexual behaviour of adolescents. Generally, empirical studies of this topic are based on parental control, and family or conjugal instability and socialization approaches. The objective of this study is to assess the association between family environment and the sexual behaviour of adolescents aged 12 to 19 years. The 2004 National Survey of Adolescents (NSA) in Burkina Faso provides data for studying operationalization. Analyses were bivariate and multivariate. The former were conducted using cross tabulations while the latter used three logistic regression models. Results indicate a significant but low association among family environment variables. Absence of both parents, or a number of individuals under 20 years old higher than the number of adults in a household is not systematically associated with risky sexual behaviour. Parental control was shown to be more discriminating of sexual behaviour of adolescents from Burkina Faso, compared with communication with family members regarding sexuality. Despite current ongoing economic crises and sociocultural mutations in Burkinabe societies, household members and family still play major roles in adolescents' education. Results reinforce sexual and reproductive health programs where parents and household members are central to strategies.
\end{abstract}

\section{Keywords}

Sexual Behaviour, Family Environment, Adolescents, Burkina Faso

\section{Introduction}

Studies conducted in Africa have demonstrated a significant association between family environment and the 
sexual behaviour of adolescents. The family environment has been considered from various viewpoints such as type of residential arrangement at time of survey or during childhood, parents alive, parents living together, parents' or guardians' marital status, living with grandparents, number of children in the household, and number of siblings. These variables were constructed from data collected in households of residence at time of survey. Most studies on this topic are characterized either by a limited definition of family environment or by leaving aside mechanisms linking familial influence and the sexual behaviour of adolescents.

In several studies, only one variable, especially type of family (or type of household) is considered for family environment. Studies by Tambashe and Shapiro [1], Rwengué [2] and Diop-Sidibé [3] looked at more than one variable. In Sub-Saharan Africa, three main factors mark the socialization practices of adolescents: the household's human configuration, the fostering of children, and whether or not parents are alive. Operationalized family environments that do not take these specifications into account might underestimate the scope of the association that is likely to exist between family environment and adolescents' behaviour. This is the case for studies carried out in Africa that focus essentially on comparing adolescents from two-parent families to those from broken families, inspired by empirical studies conducted in the West [4] [5] that are based on theoretical approaches developed in the contexts of these industrialized societies.

Some studies that focus directly or indirectly on this issue [1]-[9] do not control for family mechanisms or processes through which household members influence sexual behaviour. Such mechanisms combine relationship and communication between parents and adolescents with parental monitoring. However, since the early 2000s, the trend has been to take these mechanisms into account [10]-[15]. This new direction in research is possible because of the availability of data on family processes.

The pertinence of our study rests on the extent of risky sexual behaviours among adolescents as well as associated health problems and unwanted pregnancies. According to the 2003 Demographic and Health Survey (DHS) report for Burkina Faso, almost half of girls (48.4\%) and more than a quarter of boys (26.2\%) aged 15 to 19 have already had their first sexual relations [16]. During the most recent sexual relations of adolescents who are single, $52.9 \%$ of girls and $38.6 \%$ of boys did not use condoms. Among adolescents who had had their first sexual relations, $3.9 \%$ of girls and $11.5 \%$ of boys acknowledged having had an STI or symptoms of these infections. AIDS prevalence is $0.9 \%$ in girls and $0.7 \%$ in boys.

The high number of sexual health problems of Burkinabe adolescents is linked to the general context of lower age at puberty and higher age at marriage [17] [18]. The longer period between puberty and marriage increases the time of individuals who are exposed to sex outside marriage and to the related health, psychological, social and economic consequences. In Burkina Faso, modern contraception is seldom chosen [19] [20], which does not help reduce the frequency of these consequences.

Adolescence is also the period during which behavioural characteristics are developed and when it is possible for adults to guide young people toward values that are socially acceptable [21] and that present fewer health risks [22]. Parents, siblings and other relatives are mainly responsible for modeling behaviours. Hence, among Burkina Faso's ethnic groups, particularly the Mossi majority, children are taught about couple relationships, housekeeping, how to take care of children, appropriate attitudes towards members of society, and other issues [23]-[25]. From early childhood, people are encouraged to internalize male or female values, attitudes and practices. In Africa, gender-based socialization is a determinant of sexual behaviours presenting health risks and risks of pregnancy [26]. For example, education given to girls results in their being passive and submissive when they are involved in intimate relationships [18].

The goal of this study is to evaluate the association between family environment and adolescents' sexual behaviour. In Burkina Faso, Akoto et al. [19] had previously recommended that such a study be undertaken. However, only more recently did Karibu and Ezeh [14] followed by Biddlecom et al. [15] take this concern into consideration in their research on adolescents in Burkina Faso and three other African countries. The specificity of our study stems from the range of variables that we use to operationalize family environment and the fact that we took family processes into consideration. Generally, empirical studies on this topic are based on three theoretical approaches: socialization, parental control, and family or conjugal instability. The approach of socialization considers adolescent behaviour to be dependent upon parent-child relationship and communication. In families, biological parents are not the only ones who socialize adolescents [18] [27] [28]. Siblings, other adults and grandparents living in the household can also be involved. According to the approach of parental control, parents' objectives are to be aware of adolescents attitudes and behaviours and to monitor their activities so they can discipline adolescents who engage in socially unacceptable behaviour [29]. It is considered that in situations 
where parents are not together (single-parent families) or have remarried (blended families), parents spend less time with adolescents and consequently provide less supervision. The approach of conjugal or family instability emphasizes the situation of children in single-parent and blended families [30]. In these families, problems could negatively affect parents' relationships with their children and their capacity to offer guidance and monitor adolescents' activities. In Sub-Saharan Africa, it is more relevant to associate the situation of orphaned or fostered adolescents with this theoretical perspective.

\section{Materials and Methods}

\subsection{Data}

The 2004 National Survey of Adolescents (NSA) in Burkina Faso provides data for the study. It looks at the sexual and reproductive health of 12- to 19-year-old adolescents. The survey was organized by Institut National de la Statistique et de la Démographie in collaboration with Macro International Inc. and The Alan Guttmacher Institute [20]. It is part of a program of surveys conducted in three other countries in Sub-Saharan Africa: Ghana, Malawi and Uganda.

The NSA is a nationally representative, stratified household survey. It included 5400 households taken from a sub-sample of the 2003 Demographic Health Survey (DHS) enumeration areas, and covered populations residing in ordinary households. All adolescents aged 12 to 19 living in regular households were eligible to participate. In all, 5955 adolescents were surveyed: $49.4 \%$ girls and $50.6 \%$ boys.

Our study focuses on the evaluation of premarital sexual behaviours adopted by adolescents experiencing socialization processes in family environments. To this end, the test sample does not consider adolescents who had their first sexual relations after marriage. Also excluded are adolescents who first had sex before marriage but lived with a partner at the time of the survey, and adolescents with the status of household caregivers. In the latter two cases, household of residence at survey would not correspond to socialization setting. In all, $7.2 \%$ of adolescents were excluded from the analyses. They are mostly girls (90\%), uneducated teens (80.8\%) and adolescents aged 18 to 19 years (66.4\%) The final study sample is composed of 5458 adolescents, 976 of whom had had sexual relations.

\subsection{Variables}

\subsubsection{Dependent Variables}

Sexual behaviours were measured by first premarital sex; among adolescents who had had premarital sexual experiences, the behaviours measured were condom use at first sex, number of sex partners over the past 12 months, and systematic condom use during this period.

An adolescent's status regarding first sex (sexual relations with vaginal penetration) was determined with the following question: When did you have sex for the first time (if you have ever had sex)? Using the imputation method, data on age at first sex was defined for all adolescents who had initiated sex.

To assess condom use at first sex, the following question was asked: "When you had sex for the first time, was a male condom used?" In the NSA questionnaire for adolescents, dozens of questions were asked regarding sexual relations, partners and circumstances under which sexual relations occurred, in the past 12 months and in the past 3 months. The data collected for this purpose are summarized by "number of sex partners" and "systematic condom use" in the past 12 months. Adolescents who used a condom during all reported sexual relations are considered as having used it systematically. The variable "systematic condom use" was constructed using sexual relations in the past 12 months for girls, and sexual relations in the past 12 and past 3 months for boys. Data on context of sexual relations in the past 3 months were collected only from boys, to assess systematic condom use and its effectiveness.

A sexual behaviour presents a health risk when there is a greater likelihood of contracting sexually transmitted infections or HIV, and of pregnancy at a young age and/or unwanted pregnancy. A sexual behaviour is risky when at least one of the following conditions is met: first premarital sex at an earlier age than other respondents; not using condoms at first sex; having had at least two sex partners in the past 12 months; or not systematically using a condom during sexual relations in the past 12 months.

The operational definition of risky sexual behaviour is based on the one used by UNAIDS for the monitoring and evaluation of national AIDS and sexually transmitted infections programs [31]. Categories for sexual be- 
haviours defined as "risky" are based on a public health principles, which endeavour to get populations to adopt desirable behaviours through prevention initiatives [32].

\subsubsection{Independent and Control Variables}

The definition and measurement of the concept of family environment include parents' reproductive and conjugal path and history, which are difficult to collect; this could explain the lack of interest in such a measurement in standard survey operations that consider only household residence [33] [34]. Due to a lack of appropriate data, researchers turn to household data. "Household" is defined according to residential unit and hierarchical links among individuals [35], whereas "family" is based on blood relationship or marriage [36]. The tendency to use household data to understand the family environment is designed to facilitate measurement of the concept of family.

Family environment is represented by type of family household, parents alive, living with grandparents, and ratio of people under 20 per adult in the household. Type of household of residence distinguishes people living in the same household as the mother and father from those living with only the father or mother, or without the parents. Parents alive are based on data pertaining to the biological mother or father still living. Cohabitation with grand-parents refers to adolescents residing in households containing grand-parents and their grandchildren. There can be one or several grandparents in a household. The ratio "number of people under age 20 per adult in the household" indicates the availability of human resources for socialization of young people in a household. Adults are defined according to age criteria, that is, people aged 20 or over.

Family processes are measured by using parents' level of control and having discussed sexuality with family members. Parental level of control is an index constructed using principal component analysis (PCA) applied to the database on parents' or guardians' knowledge of adolescents' nighttime outings, what adolescents do with their free time, and who are the adolescents' friends.

There are three levels of parental control: low, medium and high. "Low level of control" includes mostly adolescents whose parents or guardians are unaware of at least two elements (night spots, leisure activities or friends), and those whose parents may be aware of all three elements. "High level of control" essentially includes adolescents who never go out and whose parents or guardians are aware of all leisure activities or know their friends, and adolescents whose parents or guardians are always aware of all three elements. Separate level of parental control variables are constructed for urban and rural settings.

The second family process variable captures the fact that an adolescent has discussed sexuality with family members, that is, mother, father, sister, brother, aunt, uncle, cousin, grandmother, grandfather, or other. The exact contents of this oral exchange on sexuality was not explored in NSA questions to adolescents.

Adolescents' sexual behaviour can also be determined by extrafamilial environment; this includes people of all ages in the community who interact with the adolescent in community settings such as schools, religious organizations, social groups, social education and health centres, or simply neighbourhoods. It is a measure of the social capital available to adolescents from the community [37] and that allows them to access information, develop knowledge, attitudes, values and behavioural models. It is measured from the perspective of the adolescent, according to level of education, participation in religious activities, belonging to social groups (association, youth group or club), number of friends of the same sex, number of friends of the opposite sex, and having talked about sexuality with someone from outside the family ${ }^{1}$.

Analyses in this study are controlled by a series of other variables: adolescent's ethnicity, place of residence, age at survey, household wealth index, and head of household's level of education. The household wealth index was constructed with PCA [38] using data on characteristics of the home, and household members' and household's assets, as well as facilities in the household. The variable is a proxy for the household's standard of living. In analyses on sexually active adolescents' behaviour, many modalities of ethnicity and age at survey are reduced due to their small numbers.. Analysis pertaining to condom use at first sexual relation is controlled for age at this event, without taking into account age at survey. Analysis of sexual behaviour in the past 12 months is controlled for duration since initiation of sexual activity, which distinguishes adolescents who initiated sexual activity in the past 12 months from those who did so more than 12 months ago. The variable stems from the difference between an adolescent's age in months at time of survey and approximate age in months at first sex. Multiplying age at first sexual relation by 12 yields this approximation.

${ }^{1}$ It is the fact of having discussed sexuality with friends, boyfriends or girlfriends, teachers, health professionals, religious leaders, or others. 


\subsection{Hypotheses}

- A family environment comprised of both parents in the household, both parents alive, grandparents, or individuals under age 20 fewer than adults in the household is less likely to be associated with risky sexual behaviour.

- Having discussed sexuality with family members or greater parental (or guardian) control is less likely to be associated with risky sexual behaviour.

- The relationship between family environment or family processes and sexual behaviour depend on the adolescent's gender.

\subsection{Methods}

Analyses were bivariate and multivariate. Cross-tabulations were used for bivariate analyses. Significance of associations between variables was assessed using chi-squared test at a threshold value of 0.05. Multivariate analyses were conducted according to three variants of logistic regression, based on dependent variable categories: discrete-time survival analysis using logistic regression (onset of premarital sexual relations), dichotomous logistic regression (condom use at first sex and systematic use in the past 12 months), and ordered logistic regression (number of sex partners in the past 12 months). Availability of data on age at first sex determined the use of discrete-time survival logistic regression to analyse first sex. To apply this method, the "episode" data file must first be changed into a "person-years" data file. Weighted data were used for the analyses. Mulitivariate analysis results are considered according to a maximum significance threshold of 0.10 .

The NSA sample design consisted of interviewing a number of 12- to 19-year-olds living in households. Logistic regression involved the assumption of adolescents' independence; this hypothesis cannot be verified in the case of the behaviours of adolescents from a same household. The same applies to analyses of person-years, which are elements in an adolescent's history. To control the correlation of observations and improve the robustness of standard errors, we used the "cluster" option in Stata for analyses involving two levels (adolescent and household), and a multilevel analysis with a random intercept for cases involving three levels (person-years, adolescent and household) using Stata 10.0 with the command xtmelogit.

\section{Results}

\subsection{Adolescents' Sexual Behaviour}

An exploration of dependent variables by sex (Table 1) provides insight into the sexual behaviour of boys and girls. Overall, $18.4 \%$ of Burkinabe adolescents reported having premarital sexual relations. Median age at first sex for boys and girls in our sample is 18.9 years, and was obtained from the survival table. According to adults in Burkina Faso, Mali and Niger, it is more common these days for young people to have sex outside marriage than when they were young themselves [39]. This point of view is consistent with the conclusions of scientific studies that puberty occurs at a younger age and age at marriage is rising, and thus sexual initiation of adolescents is more likely to be premarital. Yet, in the values of most ethnic groups in Burkina Faso, sexual relations occur within marriage [20] [23].

Among sexually active adolescents, 34.5\% reported using a condom the first time they had sexual relations. Girls were proportionately more numerous than boys to report using a condom at first sex (39.8\% vs 30.9\%). The condom is the contraceptive [19] [20] Burkinabe adolescents were most familiar with and the one they used the most. Its use at first sex was quite low, a reflection of several realities. Part of this finding can be explained by the trust partners had in each other, which justified their desire to have sexual relations. A second explanation is the cost and accessibility of condoms. Admittedly, the cost of condoms has gone down and its geographical accessibility has risen. But for a Burkinabe adolescent under 20 years of age with no source of income, it can be difficult to find the 50 or 100 CFA francs needed to by a pack of four condoms. Even when there is money, they have to be daring to go to a neighbourhood store to purchase condoms, and risk being judged by the shopkeeper and the entire neighbourhood.

In the past 12 months, $9 \%$ of adolescents who had initiated sex reported having had more than one sex partner, and $31.1 \%$ said they had systematically used a condom during sexual relations. Proportionately more boys than girls reported having had more than one sex partner (12.9\% of boys, $3 \%$ of girls). Conversely, fewer boys than girls stated having systematically used condoms (27.5\% vs 36.7\%). In the Burkina Faso context of low condom 
Table 1. Distribution of adolescents by sexual behaviour and gender ${ }^{\dagger}$.

\begin{tabular}{|c|c|c|c|c|c|c|c|}
\hline \multirow{2}{*}{ Sexual behaviour } & \multicolumn{2}{|c|}{ Boys } & \multicolumn{2}{|c|}{ Girls } & \multirow{2}{*}{ Chi $^{2}$ probability } & \multicolumn{2}{|c|}{ Both } \\
\hline & $\%$ & $\mathrm{~N}$ & $\%$ & $\mathrm{n}$ & & $\%$ & $\mathrm{n}$ \\
\hline \multicolumn{8}{|c|}{ Premarital first sex } \\
\hline No & 79.1 & 2356 & 84.5 & 2126 & 0.000 & 81.6 & 4482 \\
\hline \multirow[t]{2}{*}{ Yes } & 20.9 & 593 & 15.5 & 383 & & 18.4 & 976 \\
\hline & \multicolumn{4}{|c|}{ Condom use at first sex } & & & \\
\hline No & 69.1 & 418 & 60.2 & 239 & 0.027 & 65.5 & 657 \\
\hline Yes & 30.9 & 175 & 39.8 & 143 & & 34.5 & 318 \\
\hline \multicolumn{8}{|c|}{ Number of sex partners in the past 12 months } \\
\hline None & 29.9 & 171 & 23.3 & 85 & & 27.2 & 256 \\
\hline One & 57.2 & 346 & 73.8 & 286 & 0.000 & 63.8 & 632 \\
\hline At least two & 12.9 & 76 & 3.0 & 12 & & 9.0 & 88 \\
\hline \multicolumn{8}{|c|}{ Systematic condom use in the past 12 months } \\
\hline No & 72.5 & 438 & 63.4 & 253 & 0.021 & 68.9 & 691 \\
\hline Yes & 27.5 & 155 & 36.7 & 130 & & 31.1 & 285 \\
\hline Median age at first sex & \multicolumn{2}{|c|}{$\begin{array}{l}18.9 \text { years } \\
(\mathrm{n}=2879)\end{array}$} & \multicolumn{2}{|c|}{$\begin{array}{l}18.9 \text { years } \\
(\mathrm{n}=2579)\end{array}$} & & \multicolumn{2}{|c|}{$\begin{array}{l}19.0 \text { years } \\
(\mathrm{n}=5458)\end{array}$} \\
\hline
\end{tabular}

${ }^{\dagger}$ Weighted percentage.

use, the number of sex partners over the past 12 months could indicate sexual situations with potential health risks. We can assume that numerous adolescents who had had more than one sex partner in the past 12 months did not use condoms systematically.

Sexual behaviour varies significantly by gender, thus reflecting differences in the socialization processes of adolescents of both sexes. Girls are subject to significant control by family and community members, which limits their propensity to initiate sexual activity at a young age. Such social control persists while girls remain in a family environment under adult guardianship. They are constantly warned against out-of-wedlock pregnancies and the familial and social consequences that would ensue.

Out-of-wedlock pregnancies are a major social problem in Africa [40] [41]. According to Burkinabe adults, cases of out-of-wedlock pregnancies are common among families [42]. Their consequences cause permanent concerns for the families [21] [43]. Teen pregnancy can lead to dropping out of school, abortion, premature birth or to compromising a girl's prospects for marriage. A pregnant young girl can also be rejected by her family and socially marginalized.

\subsection{Variables Associated with Adolescents' Sexual Behaviour}

Table 2 shows the results of multivariate analyses conducted by sex. These are estimated coefficients in regression models for first premarital sex (columns 2 and 3), condom use at first sex (columns 4 and 5), systematic condom use in the past 12 months (columns 6 and 7), and number of sex partners during this period (columns 8 and 9).

\subsubsection{First Sex}

Family environment is significantly associated with girls' first sex, through type of family household. Absence of both parents from the household is associated with early first sex, compared with girls living with their two parents.

Among family process variables, level of parental control is associated with first sex of boys and girls. Medium or high level of control is associated with later first sexual intercourse. Having discussed sexuality with family members is associated with early first sex.

As for variables related to extrafamilial environment, results show that girls in high school are more likely to delay first sex. Boys who reported not belonging to a religion are more likely to have sexual intercourse at a young age. Belonging to social groups is associated with early first sex among girls. Having a higher number of friends of the same sex reduces the probability of early first sex among boys. A higher number of friends of the 
Table 2. Logistic regression models of the sexual behaviour of adolescents in Burkina faso in $2004^{\dagger}$.

\begin{tabular}{|c|c|c|c|c|c|c|c|c|}
\hline \multirow{3}{*}{ Variables } & \multicolumn{8}{|c|}{ Coefficients of regression models } \\
\hline & \multicolumn{2}{|c|}{$\begin{array}{l}\text { Premarital } \\
\text { first sex }\end{array}$} & \multicolumn{2}{|c|}{$\begin{array}{l}\text { Condom use } \\
\text { at first sex }\end{array}$} & \multicolumn{2}{|c|}{$\begin{array}{c}\text { Systematic condom } \\
\text { use in the past } 12 \\
\text { months }\end{array}$} & \multicolumn{2}{|c|}{$\begin{array}{l}\text { Number of sex } \\
\text { partners in the pas } \\
12 \text { months }\end{array}$} \\
\hline & Boys & Girls & Boys & Girls & Boys & Girls & Boys & Girls \\
\hline \multicolumn{9}{|l|}{ Family environment } \\
\hline \multicolumn{9}{|l|}{ Type of family household } \\
\hline Two parents (Ref.) & 0.00 & 0.00 & 0.00 & 0.00 & 0.00 & 0.00 & 0.00 & 0.00 \\
\hline Mother only & 0.00 & 0.30 & -0.36 & $1.72^{* *}$ & 0.34 & $2.22^{* *}$ & 0.32 & $1.11^{*}$ \\
\hline Father only & -0.10 & 0.12 & 0.42 & -0.04 & -0.17 & -0.14 & 0.06 & -0.39 \\
\hline No parent & 0.06 & $0.52^{* * *}$ & $-0.81^{*}$ & $0.79 \pm$ & -0.47 & 0.41 & -0.43 & -0.04 \\
\hline \multicolumn{9}{|l|}{ Parents alive } \\
\hline Both parents alive (Ref.) & 0.00 & 0.00 & 0.00 & 0.00 & 0.00 & 0.00 & 0.00 & 0.00 \\
\hline Father and/or mother deceased & 0.08 & -0.04 & 0.13 & -0.50 & -0.28 & -0.70 & 0.06 & -0.25 \\
\hline \multicolumn{9}{|l|}{ Living with grand-parents } \\
\hline No (Ref.) & 0.00 & 0.00 & 0.00 & 0.00 & 0.00 & 0.00 & 0.00 & 0.00 \\
\hline Yes & 0.08 & 0.11 & 0.16 & -0.05 & 0.19 & -0.02 & 0.18 & -0.53 \\
\hline Ratio of number people under age 20 per adult & 0.01 & -0.03 & 0.00 & $0.32 \pm$ & $-0.31^{*}$ & -0.04 & -0.11 & -0.01 \\
\hline Joint significance test of family environment & Not sign. & $\mathrm{p}<0.010$ & Not sign. & $\mathrm{p}<0.050$ & $\mathrm{p}<0.100$ & $\mathrm{p}<0.100$ & Not sign. & Not sign. \\
\hline \multicolumn{9}{|l|}{ Family processes } \\
\hline \multicolumn{9}{|l|}{ Level of parental control } \\
\hline Low (Ref.) & 0.00 & 0.00 & 0.00 & 0.00 & 0.00 & 0.00 & 0.00 & 0.00 \\
\hline Medium & $-0.16 \pm$ & $-0.56^{* * *}$ & -0.13 & 0.06 & -0.18 & $-0.93^{*}$ & $-0.79^{* *}$ & $-1.25^{* * *}$ \\
\hline High & $-0.46^{* * *}$ & $-0.79^{* * * *}$ & 0.29 & $1.04^{* *}$ & -0.57 & 0.29 & $-0.73^{* *}$ & -0.31 \\
\hline \multicolumn{9}{|l|}{ Having discussed sexuality with family members } \\
\hline No (Ref.) & 0.00 & 0.00 & 0.00 & 0.00 & 0.00 & 0.00 & 0.00 & 0.00 \\
\hline Yes & $0.18 \pm$ & -0.10 & 0.27 & $0.92^{*}$ & -0.05 & 0.58 & -0.22 & -0.07 \\
\hline \multicolumn{9}{|l|}{ Extrafamilial environment variables } \\
\hline \multicolumn{9}{|l|}{ Educational level completed } \\
\hline No education (Ref.) & 0.00 & 0.00 & 0.00 & 0.00 & 0.00 & 0.00 & 0.00 & 0.00 \\
\hline Elementary & 0.08 & -0.01 & -0.04 & 0.65 & 0.10 & $1.65^{* * *}$ & -0.27 & 0.01 \\
\hline High school & 0.00 & $-0.35 \pm$ & $1.05^{*}$ & $1.81^{* *}$ & 0.66 & $2.53^{* * *}$ & $-0.75^{*}$ & 0.41 \\
\hline \multicolumn{9}{|l|}{ Participation in religious activities } \\
\hline No religion & $0.38 \pm$ & 0.24 & $-3.75^{* *}$ & -0.91 & -1.51 & 0.01 & -0.65 & -0.37 \\
\hline Non-participant (Ref.) & 0.00 & 0.00 & 0.00 & 0.00 & 0.00 & 0.00 & 0.00 & 0.00 \\
\hline Participant & 0.09 & -0.12 & 0.18 & -0.21 & 0.58 & $-1,00^{* *}$ & -0.37 & -0.19 \\
\hline \multicolumn{9}{|l|}{ Belonging to social groups } \\
\hline No (Ref.) & 0.00 & 0.00 & 0.00 & 0.00 & 0.00 & 0.00 & 0.00 & 0.00 \\
\hline Yes & 0.13 & $0.27 \pm$ & 0.25 & -0.27 & -0.04 & -0.06 & 0.25 & 0.01 \\
\hline Number of friends of the same sex & $-0.03 \pm$ & -0.02 & -0.02 & 0.06 & -0.07 & -0.05 & $-0.08^{*}$ & -0.07 \\
\hline Number of friends of the opposite sex & $0.18^{* * *}$ & $0.12^{* * *}$ & 0.02 & 0.08 & $0.15^{*}$ & $0.28^{* *}$ & $0.31^{* * *}$ & 0.17 \\
\hline \multicolumn{9}{|l|}{$\begin{array}{l}\text { Having discussed sexuality with someone } \\
\text { who is not a family member }\end{array}$} \\
\hline No (Ref.) & 0.00 & 0.00 & 0.00 & 0.00 & 0.00 & 0.00 & 0.00 & 0.00 \\
\hline Yes & $0.77^{* * *}$ & $0.55^{* * *}$ & 0.07 & -0.08 & 0.17 & -0.12 & $0.65^{* *}$ & $0.73^{*}$ \\
\hline \multicolumn{9}{|l|}{ Control variables } \\
\hline /Ethnic groups & & & & & & & & \\
\hline Mossi (Ref.) & 0.00 & 0.00 & 0.00 & 0.00 & 0.00 & 0.00 & 0.00 & 0.00 \\
\hline Peul/Touareg/Bella & 0.24 & -0.28 & $-0.62^{*}$ & -0.41 & $-0.97^{* * *}$ & -0.55 & -0.07 & -0.04 \\
\hline
\end{tabular}




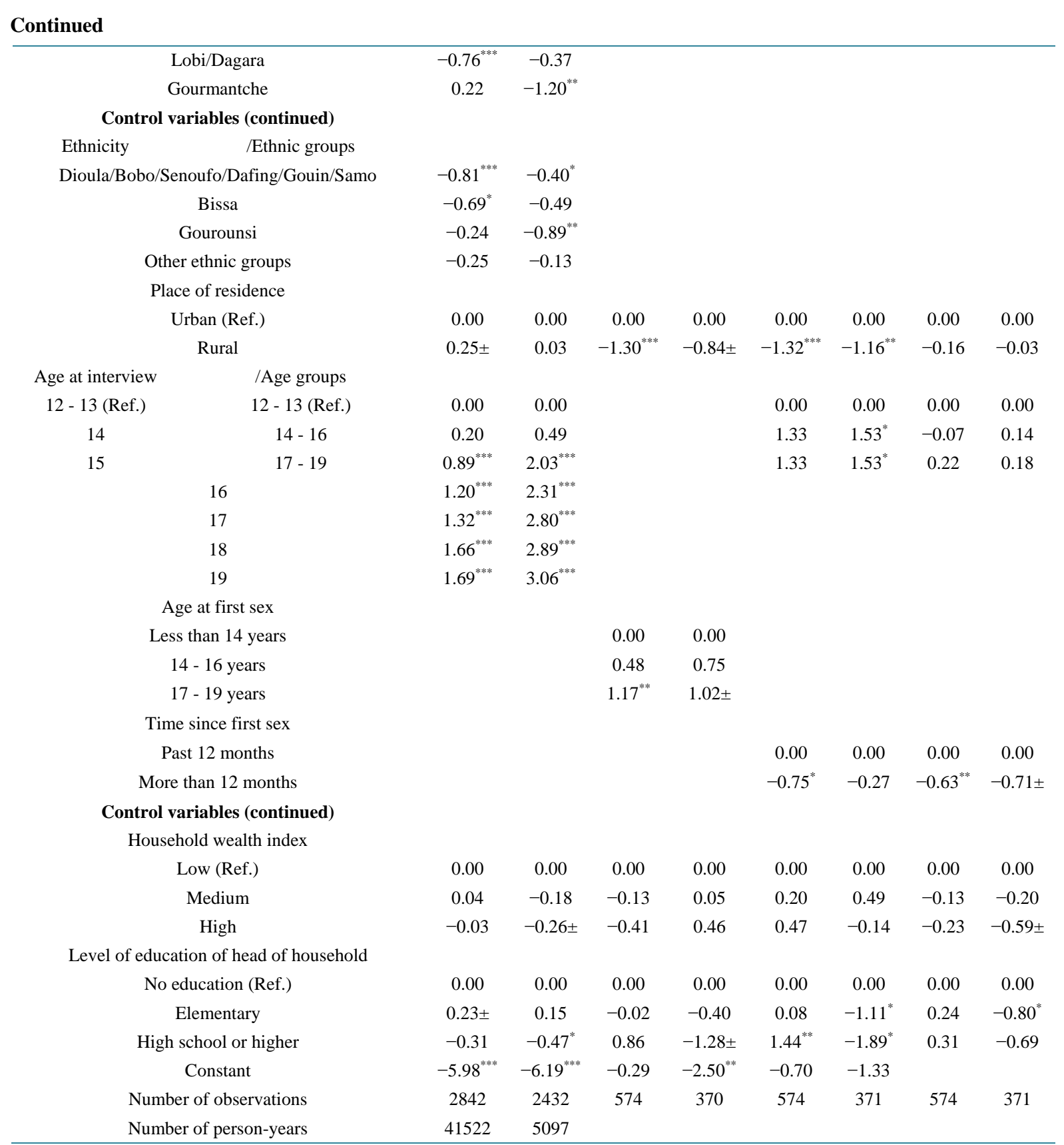

Significance level: \pm : $\mathrm{p}<0.10 ;{ }^{*} \mathrm{p}<0.05 ;{ }^{* *} \mathrm{p}<0.01 ;{ }^{* * *} \mathrm{p}<0.001$; Note: Ref.: Reference; ${ }^{\dagger}$ Weighted results.

opposite sex and having talked about sexuality with someone outside the family are associated with early first sex among boys and girls.

In the control variable categories, ethnicity, age at time of interview and level of education of the head of household are associated with initiation of sexual activity among boys and girls. Place of residence is associated in the model for boys, and household wealth index for girls.

\subsubsection{Behaviours of Adolescents Who Had Initiated Sexual Activity}

Results shown in Table 2 demonstrate a significant association between family environment and the behaviours of boys and girls who had initiated sexual relations. Boys who do not live with their parents are less likely to use condoms at first sex, compared with boys in two-parent households. Girls in the latter type of household are 
more likely to use condoms at first sex. Among girls, living with their mothers is likely to be associated with condom use at first sex, systematic condom use in the past 12 months, and having more than one sex partner during this period. An increase in the number of individuals under 20 years old per adult in the household is more likely to be associated with girls' condom use at first sex, and less likely to be associated with boys' systematic condom use in the past 12 months.

Parental control is associated with boys' and girls' behaviours, whereas having discussed sexuality with family members is only associated with girls' behaviours. High parental control over girls is associated with condom use at first sex, whereas medium parental control is less likely to be associated with systematic condom use over the past 12 months. Medium or high parental control over boys and medium control over girls is less likely to be associated with having more than one sex partner. Girls who had discussed sexuality with family members were more likely to report having used a condom at first sex.

Significant associations are observed between extrafamilial environment variables and the behaviour of adolescents who had initiated sexual relations. Boys and girls in high school are more likely to use condoms at first sex. Girls in elementary and high school are more likely to have systematically used condoms in the past 12 months. For boys, going to high school is associated with a low probability of having more than one sex partner. Boys who do not adhere to a religion are less likely to use a condom at first sex; girls who participate in religious activities are less likely to have systematically used condoms in the past 12 months. Among boys, an increase in the number of friends of the same sex reduced the probability of having had more than one sex partner over the past 12 months. An increase in the number of friends of the opposite sex is associated with systematic condom use over the past 12 months among boys and girls, and, for boys, with having had more than one sex partner. Lastly, boys and girls who reported discussing sexuality with someone outside the family are more likely to have had more than one sex partner in the past 12 months.

Among control variables, ethnicity is not significantly associated with girls' behaviours. Age at survey and household wealth index are not significantly associated with boys' behaviours.

\section{Discussion}

Analyses reveal a weak, sex-differentiated association between family environment and sexual behaviour. "Parents alive" and "living with grandparents" are not associated with sexual behaviour indicators. No new results emerged from looking at the joint effects of the variables that operationalize family environment. Our results indicated that adolescents living with both parents did not have safer sexual behaviours than those living in other types of households.

The absence of both parents in the household is not systematically associated with risky sexual behaviours in girls who lived with their mothers only or who did not live with their parents. Girls who lived with their mothers and without their fathers are more likely to have had several sex partners than their counterparts living with both parents. However, they had a greater propensity to use condoms at first sex and in the past 12 months. This result runs somewhat counter to that of Biddlecom et al. [15]. These authors observed that Ghanaian girls living with their mothers were less likely to have used a contraceptive method at most recent sexual relation. But that study focused on contraception in general, which limited the scope of comparison. Our study findings enable us to qualify the hypotheses that adolescents residing with their mothers are more likely to adopt risky sexual behaviours [44] [45]. At the very least, this hypothesis holds for having several sex partners. Mothers are closer to their daughters and more likely to listen to them and act as confidantes. This relationship of trust predisposes girls to better internalize the advice given by their mothers on risks linked to sexuality. While girls in these households have more partners, a sign of having a certain amount of freedom, their tendency to use protection is an indication of their concerns regarding risks of unwanted pregnancies or sexually transmitted infections.

Analyses demonstrate that girls who did not live in households with both their parents were more likely to engage in early first sex than their counterparts living in two-parent households. This result is similar to the findings of Karim et al. [11] in their study in Ghana, where unmarried girls aged 12 to 24 who did not live with both their parents were more inclined to initiate sexual relations. Girls who do not live with both parents are entrusted to somebody's care. Their propensity to have sexual intercourse at an early age is a consequence of the heads of households' discriminatory practices when caring for children they have taken in [46] [47]. Unlike the children of heads of households, these girls get very little emotional, material and financial support. They have male companions to compensate for this lack of support. Results also show that a condom is more likely to be 
used at first sex, indicating better knowledge of the health and social consequences of having unprotected sex. Unlike girls, boys living in this same type of household do not have such knowledge or, at the very least, such awareness. They are less likely to use a condom at first sex.

According to social capital hypotheses [48], a higher number of children in a household reduce the attention and affection parents give to each child, and therefore are likely to be associated with risky sexual behaviours. Results for boys fit this hypothesis. An increase in the number of individuals under 20 years old per number of adults in the household is less likely to be associated with systematic condom use in the past 12 months. This is not the case for girls. Girls who live in this type of household are more likely to use condoms at first sex. A greater number of children and adolescents in a household is synonymous with greater proximity and better interaction among them [28] [49]. It is easier for girls who live most of their adolescence inside the household to find someone among the other young people to talk about sexuality and its consequences. The inverse is observed among boys. Such closeness encourages them to value unprotected sex.

Results related to parental control support our study hypothesis. Parental control is associated with later first sex, with having fewer than two sex partners in the past 12 months for boys and girls, and with condom use at first sex for girls. These findings are in line with the results of other studies which have shown that parental control is less likely to be associated with sexual relations in the past months [13] [15] and more likely to be associated with using a condom at most recent sexual relation [50]. However, our study demonstrates that parental control is less likely to be associated with systematic condom use in the past 12 months. This result can be explained by an inverted relationship between parental control and sexual behaviour. It is likely that higher parental control follows from adolescents' adoption of a type of behaviour.

The hypothesis of the protective effects of adolescents and family members discussing sexuality is partly borne out. The fact of having discussed sexuality is associated with girls' condom use at first sex. Similar to parental control, the effects of the last variable also suggest inverse causality. A predisposition of household members or of adolescents to talk about sexuality could result from an adolescent's sexual activity. For instance, boys who initiated sex at an early age where more likely to report having talked about sexuality with family members. Babalola et al. [12], Kumi-Kyereme et al. [13] and Biddlecom et al. [15] obtained similar results.

Compared with parental control, the variable operationalizing communication is nonetheless weakly associated with sexual behaviour. It is important to note the low accuracy of the data used to operationalize communication. The indicator variable was constructed using answers to the following question: Did you talk about issues related to sexuality with any family members? If the answer was Yes, a second question was asked: With whom did you talk about it? Results demonstrate that within households, monitoring adolescents and their activities is more commonly used by parents and guardians [20] [51]. Whether control is exercised prior or subsequent to adolescents' adopting a behaviour, these results uphold the evidence indicating a preference for monitoring adolescents.

The relationship between type of family and sexual behaviour differs according to sex. This result can be compared to those of Karim et al. [11] and Biddlecom et al. [15]. In the first study, there is an association between type of family and first sex for girls. No significant association was observed between type of family and first sex for boys. In the second study, type of family is associated only with Ghanaian and Ugandan girls' sexual behaviour. Sociocultural context explains the variations in results by gender. In Burkinabe societies, because of the importance given to girls' virginity before marriage and management of the consequences of out-of-wedlock pregnancies, household members pay greater attention to girls' sexuality.

\section{Conclusions}

The results support the hypothesis of a link between extrafamilial environment and sexual behaviour of adolescents. They highlight the importance of extrafamilial institutions, especially modern schools and religious denominations in adolescents' socialization. In Burkina Faso, parents recognize that adolescents are more predisposed to listen to a teacher's advice rather than their own [23].

Despite current ongoing economic crises and sociocultural mutations in Burkinabe societies, the family still plays a major role in adolescents' education. More discriminating aspects are the presence or absence of the father and/or mother in the household and parents' or guardians' control over adolescents, with regard to sexual behaviour. Fear of parental authority, advice and warnings, as well as psychological, emotional, financial and material support from family members limit the propensity for early sex and unprotected sexual relations. 
Results provide arguments that support using household data to examine the relationship between family environment and adolescents' behaviours. They reinforce sexual and reproductive health programs that place parents and family members at the centre of strategies [52]. The ease with which households can be located, compared with families, makes it easier to operationalize these strategies.

\section{References}

[1] Tambashe, B.O. and Shapiro, D. (1996) Family Background and Early Life Course Transitions in Kinshasa. Journal of Marriage and the Family, 58, 1029-1037. http://dx.doi.org/10.2307/353989

[2] Rwengue, M. (2000) Comportements sexuels à risques parmi les jeunes de Bamenda, au Cameroun. Perspectives Internationales sur le Planning Familial. Numéro Spécial, 13-19.

[3] Diop-Sidibé, N. (2005) Siblings’ Premarital Childbearing and the Timing of First Sex in Three Major Cities of Côte d’Ivoire. International Family Planning Perspectives, 31, 54-62. http://dx.doi.org/10.1363/3105405

[4] Miller, B.C., Benson, B. and Galbraith, K.A. (2001) Family Relationships and Adolescent Pregnancy Risk: A Research Synthesis. Developmental Review, 21, 1-38. http://dx.doi.org/10.1006/drev.2000.0513

[5] Tinsley, B.J., Lees, N.B. and Sumartojo, E. (2004) Child and Adolescent HIV Risk: Familial and Cultural Perspectives. Journal of Family Psychology, 18, 208-224. http://dx.doi.org/10.1037/0893-3200.18.1.208

[6] Toroitich-Ruto, C. (1997) The Determinants of Teenage Sexuality and their Understanding of STDs/HIV/AIDS in Kenya. Etude de la Population Africaine, 2, 14.

[7] Ngom, P., Magadi, M.A. and Owuor, T. (2003) Parental Presence and Adolescent Reproductive Health among the Nairobi Urban Poor. Journal of Adolescent Health, 33, 369-377. http://dx.doi.org/10.1016/S1054-139X(03)00213-1

[8] Thurman, T.R., Brown, L., Richter, L., Maharaj, P. and Magnani, R. (2006) Sexual Risk Behavior among South African Adolescents: Is Orphan Status a Factor? AIDS and Behavior, 10, 627-635. http://dx.doi.org/10.1007/s10461-006-9104-8

[9] Kayembe, K.P., Mapatano, M.A., Busangu, F.A., Nyandwe, K.J., Mashinda, K.D., Musema, M.G., Kibungu, J.P., Matamba, T.L. and Mayala, M.G. (2008) Correlates of Ever Had Sex and of Recent Sex among Teenagers and Young Unmarried Adults in the Democratic Republic of Congo. AIDS Behaviour, 12, 585-593.

http://dx.doi.org/10.1007/s10461-007-9290-z

[10] Magnani, R.J., Karim, A.M., Weiss, L.A., Bond, K.C., Lemba, M. and Morgan, G.T. (2002) Reproductive Health Risk and Protective Factors among Youth in Lusaka, Zambia. Journal of Adolescent Health, 30, 76-86. http://dx.doi.org/10.1016/S1054-139X(01)00328-7

[11] Karim, A.M., Magnani, R.J., Morgan, G.T. and Bond, K.C. (2003) Reproductive Health Risk and Protective Factors among Unmarried Youth in Ghana. International Family Planning Perspectives, 29, 14-24. http://dx.doi.org/10.2307/3180997

[12] Babalola, S., Tambashe, B.O. and Vondrasek, C. (2005) Parental Factors and Sexual Risk-Taking among Young People in Côte d’Ivoire. African Journal of Reproductive Health, 9, 49-65. http://dx.doi.org/10.2307/3583160

[13] Kumi-Kyereme, A., Awusabo-Asare, K., Biddlecom, A. and Tanle, A. (2007) Influence of Social Connectedness, Communication and Monitoring on Adolescent Sexual Activity in Ghana. African Journal of Reproductive Health, 11, 133-147. http://dx.doi.org/10.2307/25549736

[14] Karibu, C.W. and Ezeh, A. (2007) Factors Associated with Sexual Abstinence among Adolescents in Four Sub-Saharan African Countries. African Journal of Reproductive Health, 11, 111-132. http://dx.doi.org/10.2307/25549735

[15] Biddlecom, A., Awusabo-Asare, K. and Bankole, A. (2009) Role of Parents in Adolescent Sexual Activity and Contraceptive Use in Four African Countries. International Perspectives on Sexual and Reproductive Health, 35, 72-81. http://dx.doi.org/10.1363/3507209

[16] INSD (Institut National de la Statistique et de la Démographie) et ORC Macro (2004) Enquête démographique et de santé du Burkina Faso 2003. INSD et ORC Macro, Calverton, Maryland.

[17] Bozon, M. (2003) À quel âge les femmes et les hommes commencent-ils leur vie sexuelle? Comparaisons mondiales et évolutions récentes. Population et société, 391, 4 p.

[18] NRCIM (National Research Council and Institute of Medecine) (2005) Growing Up Global: The Changing Transitions to Adulthood in Developing Countries. Panel on Transitions to Adulthood in Developing Countries. In: Lloyd, C.B., Ed., Committee on Population and Board on Children, Youth, and Families, Division of Behavorial and Social Sciences and Education, National Academies Press, Washington DC, 700 p.

[19] Akoto, E.M., Tambashe, B.O., Amouzou, J.A. and Tameko, D.T. (2000) Sexualité, contraception et fécondité des adolescents au Burkina Faso. Projet régional santé familiale et prévention du sida (SFPS), Abidjan, 49 p. 
[20] Guiella, G. and Woog, V. (2006) Santé sexuelle et de la reproduction des adolescents au Burkina Faso: Résultats de l’Enquête Nationale sur les Adolescents du Burkina Faso 2004. Occasional Report No. 21, Guttmacher Institute, New York.

[21] Ouedraogo, C., Woog, V. and Ouedraogo, O. (2007) Les adultes face aux comportements sexuels des adolescents: Difficultés et enjeux. Occasional Report, No. 32, Guttmacher Institute, New York.

[22] Selikow, T.A., Ahmed, N., Flisher, A.J., Mathews, C. and Mukoma, W. (2009) I Am Not "Umqwayito": A Qualitative Study of Peer Pressure and Sexual Risk Behaviour among Young Adolescents in Cape Town, South Africa. Scandinavian Journal of Public Health, 37, 107-112. http://dx.doi.org/10.1177/1403494809103903

[23] Guira, A. (1983) Enquête sociologique sur la sexualité en milieu traditionnel. Institut National pour l’Alphabétisation et la Formation des Adultes (INAFA), Ouagadougou.

[24] Kobiané, J.F. (2003) Pauvreté, structures familiales et stratégies éducatives à Ouagadougou. In: Cosio, M., Marcoux, R., Pilon, M. and Quesnel, A., Eds., Éducation, famille et dynamiques démographiques, CICRED, Paris, 153-182.

[25] Helmfrid, S. (2004) Profil genre du Burkina Faso. Vers l'égalité entre les genres au Burkina Faso. ASDI (Agence Suédoise de Coopération Internationale au Développement) Département pour l’Afrique, Stockholm, 91 p.

[26] Okonofua, F. (2001) La Socialisation Selon les Sexes: Un Problème Négligé dans le Domaine de la Santé Sexuelle et Reproductive en Afrique. La Revue Africaine de la Santé Reproductive, 5, 7-10.

[27] Llyod, C.B. and Desai, S. (1992) Children's Living Arrangements in Developing Countries. Population Research and Policy Review, 11, 193-216. http://dx.doi.org/10.1007/BF00124937

[28] Amuyunzu-Nyamongo, M., Biddlecom, A.E., Ouedraogo, C. and Woog, V. (2005) Qualitative Evidence on Adolescents' Views on Sexual and Reproductive Health in Sub-Saharan Africa. Occasional Report No. 16, Alan Guttmacher Institute, New York, 49 p.

[29] WHO (World Health Organization) (2002) Broadening the Horizon: Balancing Protection and Risk for Adolescents. Geneva.

[30] Albrecht, C. and Teachman, J.D. (2003) Childhood Living Arrangements and the Risk of Premarital Intercourse. Journal of Family Issues, 24, 867-894. http://dx.doi.org/10.1177/0192513X03252731

[31] UNAIDS (United Nations Programme on HIV/AIDS) (2000) National AIDS Programmes: A Guide to Monitoring and Evaluation. UNAIDS Document 00/17E, Geneva.

[32] Calvez, M. (2001) Le risque comme ressource culturelle dans la prévention du sida. In: Dozon, J.P. and Fassin, D., Eds., Critique de la santé publique. Une approche anthropologique, Balland, Paris, 127-144.

[33] Lefranc, C. and Thave, S. (1994) L’évolution de l'environnement familial des enfants. Population, 49, 1297-1320. http://dx.doi.org/10.2307/1534011

[34] Marcil-Gratton, N., Juby, H., Le Bourdais, C. and Lapierre-Adamcyk, E. (2006) La démographie de l'enfance: Entre familles et résidences. In: Enfants d'aujourd'hui: Diversité des contextes, pluralité des parcours. Actes du Colloque international de Dakar (2002), Association internationale des démographes de langue française (AIDELF), Presses Universitaires de France, Collection “AIDELF”, No. 11, Tome 1, Paris, 35-43.

[35] Sala-Diakanda, D. (1988) Problèmes conceptuels et pratiques liés aux informations disponibles sur la structure des ménages en Afrique ainsi qu'à son analyse. In: Congrès africain de population, UIESP, Dakar novembre 1988, Liège, $1-16$.

[36] Waite, L.J. (2003) Marriage and Family. In: Poston, D.L. and Micklin, M., Eds., Handbook of Population, Springer, Berlin, 87-108.

[37] Leonard, M. (2005) Children, Childhood, and Social Capital: Exploring the Links. Sociology, 39, 605-622. http://dx.doi.org/10.1177/0038038505052490

[38] Rutstein, S.O. and Kiersten, J. (2004) The DHS Wealth Index. DHS Comparative Reports No. 6, ORC Macro, Calverton, Maryland.

[39] CERPOD (Centre d’Études et de Recherche sur la Population pour le Développement) (1996) Les jeunes en danger. Résultats d'une étude régionale dans cinq pays de l'Afrique de l'ouest. In: Santé de la Reproduction au Sahel, CERPOD, Bamako, 48 p.

[40] Gyepi-Garbrah, B. (1985) Adolescent Fertility in Sub-Saharan Africa: An Overview. The Pathfinder Fund, Boston, Massachusetts.

[41] Adjamagbo, A., Antoine, P. and Delaunay, V. (2004) Naissances prémaritales au Sénégal: Confrontation de modèles urbain et rural. Cahiers québécois de démographie, 33, 239-272. http://dx.doi.org/10.7202/011206ar

[42] Ouedraogo, C., Woog, V. and Sondo, G. (2006) Expériences d'adolescents en santé sexuelle et reproductive au Burkina Faso. Occasional Report No. 20, Guttmacher Institute, New York.

[43] Gorgen, R., Maier, B. and Diesfeld, H.J. (1993) Problems Related to Schoolgirl Pregnancies in Burkina Faso. Studies 
in Family Planning, 24, 283-294. http://dx.doi.org/10.2307/2939222

[44] McLanahan, S. and Bumpass, L. (1988) Intergenerational Consequences of Family Disruption. American Journal of Sociology, 94, 130-152. http://dx.doi.org/10.1086/228954

[45] Amato, P.R. (1993) Children's Adjustment to Divorce: Theories, Hypotheses, and Empirical Support. Journal of Marriage and the Family, 55, 23-38. http://dx.doi.org/10.2307/352954

[46] Jonckers, D. (1997) Les enfants confiés. In: Pilon, M., Locoh, T., Vignikin, E. and Vimard, P., Eds., Ménages et familles en Afrique. Approches des dynamiques contemporaines. Les études du CEPED, No. 15, CEPED, Paris, 193208.

[47] Younoussi, Z. (2007) Les déterminants démographiques et socio-économiques du confiage des enfants au Burkina Faso. African Population Studies, 22, 203-231.

[48] Coleman, J.S. (1988) Social Capital in the Creation of Human Capital. The American Journal of Sociology, 94, S95S120. http://dx.doi.org/10.1086/228943

[49] Haurin, R.J. and Mott, F.L. (1990) Adolescent Sexuality in the Family Context: The Impact of Older Siblings. Demography, 27, 537-557. http://dx.doi.org/10.2307/2061569

[50] Twa-Twa, J.M., Oketcho, S., Siziya, S. and Muula, A.S. (2008) Prevalence and Correlates of Condom Use at Last Sexual Intercourse among in School Adolescents in Urban Areas of Uganda. East African Journal of Public Health, 5, 22-25. http://dx.doi.org/10.4314/eajph.v5i1.38972

[51] Badini, A. (1994) Naître et grandir chez les Moosé traditionnel. Sepia/ADDB, Paris-Ouagadougou.

[52] WHO (World Health Organization) (2008) Helping Parents in Developing Countries Improve Adolescents’ Health. Geneva. 